\title{
Evaluation of the effects of a leader-training program on public health nurse leadership for staff in Japan
}

\author{
Izumi Ueda $^{{ }^{*}}$, Kazuko Saeki ${ }^{2}$, Mariko Kawaharada ${ }^{2}$, Michiyo Hirano ${ }^{2}$, Miyuki Seki ${ }^{3}$, \\ Hisako Izumi $^{1}$ \\ ${ }^{1}$ Department of Nursing, Sapporo Medical University, Sapporo, Japan \\ ${ }^{2}$ Faculty of Health Science, Hokkaido University, Sapporo, Japan \\ ${ }^{3}$ Department of Nursing, Saitama Prefectural University, Koshigaya, Japan \\ Email: ${ }^{*}$ iueda@sapmed.ac.jp
}

Received 20 June 2012; revised 18 July 2012; accepted 29 July 2012

\begin{abstract}
This paper is a report of a study of the effects of a leader-training program, focusing on how public health nurse (PHN) leaders manage staff. In Japan, a system of training after graduation or training after acquisition of the PHN license has not been established. At present, PHN leaders are unable to devote as much time as they previously could to in-service education, and this has made it difficult to establish a suitable full-fledged in-service education system. Therefore, it is paramount for PHN leaders to acquire the necessary competence to train staff efficiently and, ultimately, play a more prominent role in the in-service education of novice PHNs. The effectiveness of this program was evaluated before and after conducting the program over a 1-year period. A total of 145 leaders working for local government agencies in Japan participated in the program, and data from 87 participants were analyzed. Before the training program, Plan-Do-Check-Act cycle activities were less frequent than after the program. Intervention using a leader-training program that combines group and onthe-job training is effective for PHN leaders.
\end{abstract}

Keywords: PHN Leaders; Leader-Training Program; In-Service Education; Management Practice; Japan

\section{INTRODUCTION}

In Japan the law requires licenses for public health nurses (PHNs) that are separate and different from those for other nurses. PHNs have been employed at health centers using the official title of Public Health Nurse since the enactment of the Health Center Law in 1937. The majority of PHNs work in the health sections of lo-

${ }^{*}$ Corresponding author. cal prefectural and municipal governments. Although the purview of PHNs has been expanded to the private sector and includes long-term care insurance facilities, Occupational and Environmental Health centers, and home-visit care services, 80 percent of PHNs are presently working for local governments [1].

Recent years have seen large changes in the organization of local governments, associated with the consolidation and reorganization of municipalities. Before these changes, almost all PHNs were assigned to health sections. However, with decentralization in the placement of PHNs, small numbers (one or two per organization or facility) of PHNs have been placed in various domains such as welfare, education, and long-term care insurance sections [2]. PHNs in Japan are civil service employees who are responsible for the health and welfare services at public health centers in local government organizations. Therefore, PHNs need to have an understanding of the background of health care and welfare administration as well as carry out various administrative tasks. The duties of a PHN involve a range of activities related to health care, welfare, and disease prevention within the framework of administrative services. They must develop appropriate measures to respond to social changes and community needs [3]. In recent years, PHNs have been expected to be actively involved in services related to long-term care insurance and newly emerging issues such as child abuse. To respond to these new obligations, it is necessary for PHNs to improve both their professional competence and administrative skills [4].

In Japan there are three kinds of education for training PHNs: undergraduate university programs, special study programs at junior colleges, and vocational colleges. Presently, 195 schools, including 157 undergraduate programs (May 2008), offer PHN training programs. In undergraduate programs, students can qualify as candidates for examinations for both the nursing license and the 
public health nurse license. However, PHN education suffers from inadequate length of time and limitations in the content taught, and consequently, novice PHNs display a lack of competence [5]. Ongoing education and training has become an important issue, but a comprehensive system for training after graduation or training after acquisition of the PHN license has not been established.

Currently, with the promotion of decentralization, PHNs are busy attending to increasingly complex duties. Thus, PHN leaders have less time than previously, which has created serious problems for in-service education of novice PHNs and made it difficult to establish a suitable system for such education. As a result, it is paramount for PHN leaders to acquire the competence necessary to quickly and efficiently train staff and develop a system for the in-service education of novice PHNs.

To address this issue, the authors designed and implemented a leader-training program, aiming to improve PHN leaders' competence with respect to in-service training. The objective of this study was to evaluate changes in how PHN leaders train staff members before and after taking part in the program, and to examine its overall effecttiveness.

Having a grounding in public health nursing is not sufficient to improve the competence of a PHN; therefore, on-going in-service education after graduation is necessary [6]. With advancement and specialization in the field of medicine, establishing a continuous and systematic education program will ensure the public's continued trust in the nursing profession $[7,8]$.

Most studies evaluating leader-training programs for in-service education deal with research and study results of education that directly relates to duties in the workplace such as on-the-job training (OJT). It has also been reported that, through a combination of OJT and offthe-job training (Off-JT), many programs for health care workers outside of urban centers or in mid-management positions have been successful in promoting skill-training plans to help novice PHNs to expand their role and function [9]. The unique characteristic of such programs is that theory is supported by experience, which is then applied in the workplace. In Japan, studies and research on training programs for novice PHNs are being encouraged and their number is increasing. However, to improve the current education system, PHN leaders will be called upon to play a crucial leadership role until a systematic program is established. The authors designed and implemented a leader-training program, which aimed to improve the PHN leaders' competency for talent training. The aim of this study was to evaluate the changes in PHN leaders' management practice toward individual staff before and after intervention, and to examine the overall effectiveness of this program.

\section{METHODS}

\subsection{Design and Sample}

The authors designed and implemented a leader-training program that took approximately one year from April 2006 to March 2007 and evaluated its effectiveness based on the theory of competence learning. In the United States, a skill called a "competency" is considered an efficient tool for designing personnel systems or assessment systems for hospitals and companies [10]. According to the theory of competence learning, competence can be acquired through the following processes: 1) understanding the connection between actions and results; and 2) by considering the relationship between the action-result and the work environment, competence can be developed by reviewing new insightful thinking and conceptualizations through repeated trial and error.

The subjects of this study were 145 PHN leaders with 10 years or more of experience working for prefectural governments or municipalities in four prefectures. More specifically, these PHNs were in administrative positions, or serving as chief PHNs, assistant managers, or group leaders who would move on to administrative positions.

\subsection{Design and Implementation of the Program}

The program was designed by a project team composed of researchers from universities, administrative PHNs, and personnel in charge of education in the prefectural governments and municipalities in the four prefectures. Members of the project team in each field implemented the program by following their designated roles. Group training was provided by university researchers.

To improve PHN leader competence for staff training, it was possible for learners to repeat their training by combining group training and OJT so that the required learning could be done without delays. PHN leaders could learn through experience by making plans for OJT, carrying them out and evaluating performance in the workplace. Group training and OJT (Figure 1) were employed. Group training was conducted three times in the one-year program: in the first to second, fifth to sixth, and tenth to twelfth months after the start of the program. Details and times of the group training are shown in Figure 1. Each member of the training group spent about 3 hours on lectures and group work. In the group training, tools for training specific skills, making and implementing plans, and for evaluation of the skills, were provided. This process of training was considered to be the basis for improvements to PHN leader competence as it related to managing staff.

Members of the project team conducted follow-up training at the midpoint of the research period. The follow-up method consisted of two types of evaluation: 


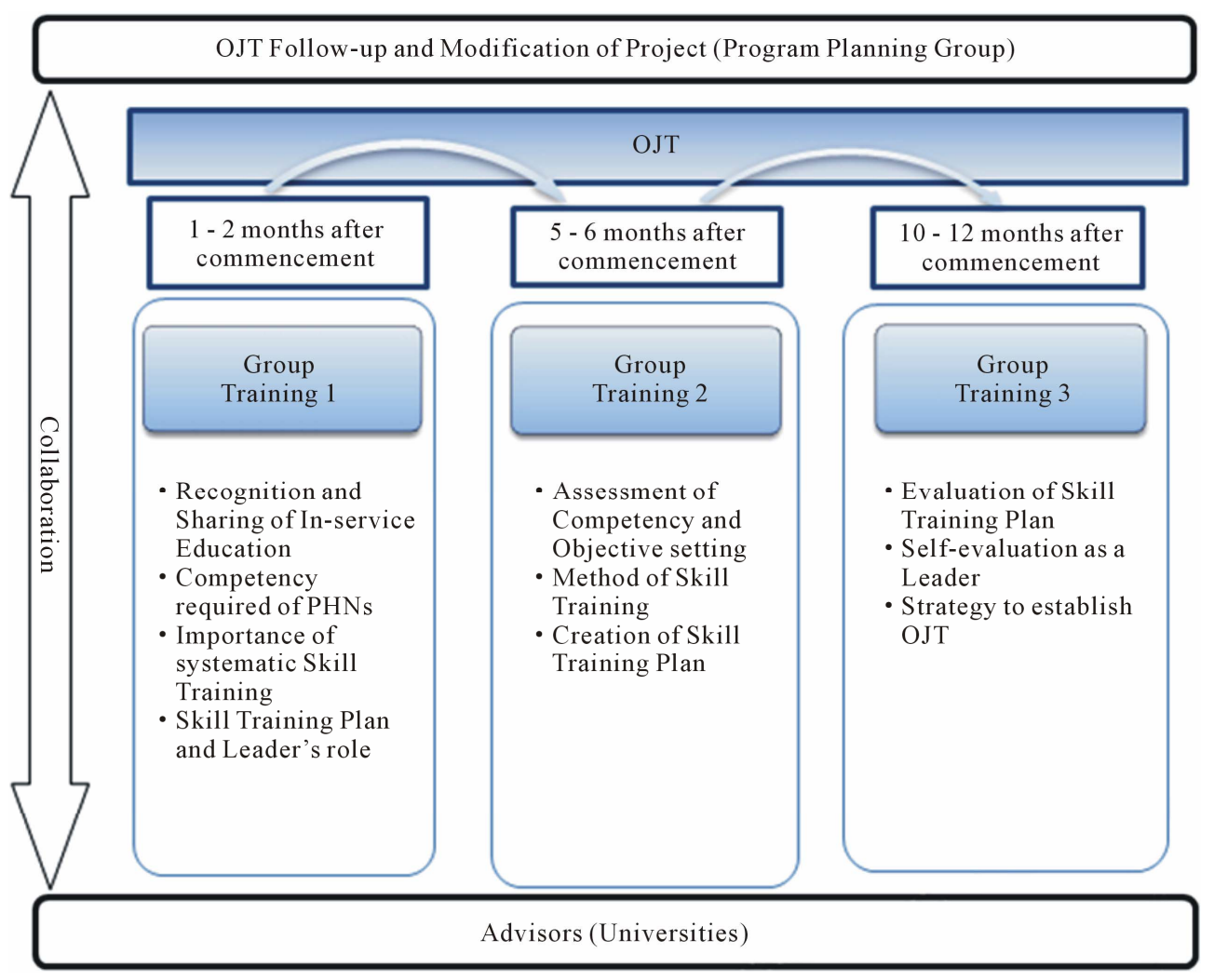

Figure 1. Outline of leader training program. OJT (on-the-job training); slender arrow (workplace performance in combining theory with practice).

conducting a workshop and visits to the workplace. In the group training, experience in skills training was shared and evaluated in a group work setting.

\subsection{Measurements}

Both the program and changes in the work environment were evaluated. For the leader-training program, the members of the project team formed a study committee and discussed the effectiveness of the training implementation methods after the completion of the third group training session. For changes in the work environment, the authors established a list of items relating to how the in-service education was conducted in the workplace and how the subjects evaluated the changes.

This study evaluated PHN leader competence in managing staff before and after the program was conducted, using self-administered questionnaires. The first questionnaire was distributed by mail or at the time of the group survey in February 2006 before commencement of the program, while the second questionnaire was distributed by mail 10 to 12 months after the program end. Evaluation was also conducted immediately after the completion of the program because it was necessary to determine the changes which had occurred and because there was a possibility that the participating PHNs might be transferred, which would make it impossible to conduct a survey one year after completion of the program for these participants.

Items for investigation in the questionnaire dealt with specific actions assumed to be necessary for a manager to perform. By definition, staff management means activities which leaders encourage individuals to do to achieve their objectives [11]. Staff management is based on activities related to the process of accomplishing tasks such as, defining individual objectives, orienting staff to define objectives, confirming details of the activity, and evaluating the results. Personal interviews are one of the methods used to confirm the definition of objectives and evaluation of results. Positive acceptance is an effective coaching approach when used to actively motivate staff as well as to promote the full Plan-Do-Check-Act (PDCA) cycle in skills training [12].

Questionnaires had eight items for personal attributes and management practices. The items for management practices consisted of two categories: the PDCA cycle activity and the coaching approach. The PDCA cycle activity had five items: defining objectives, orientation to the objectives, confirmation and advice on the objectives, evaluation of effort, and personal interviews. The coaching approach had three items: having a positive approach towards the ideas of staff members, identifying and in- 
forming staff about personal changes, and advice for self-reflection. Respondents indicated their responses on a Likert-type scale assigning the frequencies of management practices as follows: 1 "Never"; 2 "Rarely"; 3 "Sometimes"; and 4 "Always." The results of the comparison of before and after the program were binarized, and the "Sometimes" and "Always" responses (3 and 4) were categorized as the Practical Group whereas the "Rarely" and "Never" responses (1 and 2) were categorized as the Non-practical Group.

\subsection{Data Analysis}

A total of 135 responses were obtained for analysis. Eight respondents had less than 10 years of experience. Thirty-five respondents were not qualified to answer the questionnaire after completing the program because they missed important sections of the group training due to work commitments, and six respondents did not complete the questionnaire. These 49 respondents were excluded, leaving data from 86 respondents. There were no significant differences between the 86 respondents and the 49 respondents excluded from the analysis regarding management practices before the program. McNemar's test (SPSS14.0J for Windows) was used for pre- to postcomparison of the data for the 86 respondents. The significance level was set at less than $5 \%$.

\subsection{Ethical Considerations}

In adherence to regulations, permission was obtained from the ethics committee to use signed questionnaires. Subjects who participated in this study did so strictly on a voluntary basis. Each subject had the details and objectives of the study explained before consent was requested and data were statistically processed and analyzed by assigning each subject an ID number. Every effort was made to ensure the subjects' privacy and to protect confidentiality of personal information. Permission from the ethics committees of the universities to which the researchers belonged was also obtained.

\section{RESULTS}

\subsection{Evaluation of the Leader-Training Program}

This section of the evaluation of the leader-training program focuses on how PHN leaders manage staff members. How in-service education has been conducted by PHN leaders has been reported in the past [13]. Members of the project team evaluated the implementation method for the leader-training program of the study as being effective. Prior to this project the workplaces to which the participants belonged had no specific system with which to train PHN leaders. However, the personnel concerned became aware of the necessity to train PHN leaders through completing the project, resulting in the establishment of training systems in all the places of work. Consequently, PHN leader-training programs were continued after the completion of the group training reported here.

\subsection{Demographic Details of Subjects}

Table 1 shows details of the 86 PHNs whose data were analyzed. Age ranged from 31 to 59; the majority being between 40 and 49 (55.8\%) (average age 46.2 years). Academic backgrounds were as follows: graduates of nursing schools or vocational colleges: $76.7 \%$; graduates from junior colleges or colleges: $23.3 \%$. Of the participants, $55.6 \%$ supervised five or fewer staff members, whereas $44.4 \%$ supervised six or more.

\subsection{PHN Leader Awareness of the Importance of In-Service Education}

The responses of the PHN leaders were compared in a survey conducted twice; before and after the in-service education program. Before the program 93.4\% answered "in favor" to the question, "How important do you feel it is to have in-service education at your place of work?", with $6.6 \%$ not in favor. After the program, the corresponding numbers were $94.5 \%$ and $5.5 \%$, respectively. Before the program $87.8 \%$ answered "Yes" to the question, "Do you have any difficulty in conducting in-service education at your workplace?", whereas $12.2 \%$ answered "No." After the program these numbers were $90.0 \%$ and $10.0 \%$, respectively. Before the program, $83.3 \%$ answered "Yes" to the question, "Do you often feel it is necessary for your staff to have in-service education as a PHN?", whereas $17.7 \%$ answered "No". After the program these numbers were $83.4 \%$ and $16.6 \%$, respectively. Before the program, 46.6\% answered "Yes" to the question, "Do your staff members define their own objectives?", whereas 53.4\% answered "No." After the program the corresponding figures were $62.2 \%$ and $37.8 \%$, respectively.

\subsection{PHN Leaders' Management Practices Regarding Individual Staff Members}

Table 2 shows the management practices carried out before and after the program. After the program, the frequency of management skills employed by the Practical group increased for all the items. Two items, "having a positive approach towards staff ideas" and "advice for staff for self-reflection", which were frequent in the coaching approach before the program, increased by approximately $8 \%$. "Identifying and informing about personal changes" remained almost unchanged. The items, "defining individual objectives", "orienting staff to define 
Table 1. Demographic data.

\begin{tabular}{|c|c|c|c|}
\hline & & No. of persons & $\mathrm{n}=86(\%)$ \\
\hline \multirow{4}{*}{ Age } & $\leq 39$ years & 12 & 14.0 \\
\hline & $40-49$ & 48 & 55.8 \\
\hline & $\geq 50$ & 26 & 30.2 \\
\hline & $10-19$ & 30 & 34.9 \\
\hline \multirow[t]{3}{*}{ Years of experience } & $20-29$ & 46 & 53.5 \\
\hline & 30 years or more & 10 & 11.6 \\
\hline & Prefectural government & 34 & 39.5 \\
\hline \multirow[t]{3}{*}{ Organizations to which subject belongs } & Municipality & 37 & 54.7 \\
\hline & Ordinance-designated city & 5 & 5.8 \\
\hline & Assistant manager or higher & 19 & 22.1 \\
\hline \multirow[t]{2}{*}{ Job title } & Assistant chief or higher & 45 & 52.3 \\
\hline & General level & 22 & 25.6 \\
\hline \multirow{2}{*}{ Rearranged/transfer experience } & Yes & 63 & 73.3 \\
\hline & Never & 23 & 26.7 \\
\hline \multirow{2}{*}{$\begin{array}{l}\text { Experience of attending } \\
\text { skill-training/manager-training workshops }\end{array}$} & Yes & 30 & 34.9 \\
\hline & Never & 56 & 65.1 \\
\hline \multirow{2}{*}{ Is staff training your duty? } & Yes & 38 & 44.2 \\
\hline & No & 48 & 55.8 \\
\hline \multirow{2}{*}{$\begin{array}{l}\text { Do you have offer good practical } \\
\text { examples for in staff training? }\end{array}$} & Yes & 50 & 58.1 \\
\hline & No & 36 & 41.9 \\
\hline \multirow{2}{*}{ Academic background } & $\begin{array}{l}\text { Graduated from nursing school } \\
\text { or vocational college }\end{array}$ & 50 & 76.7 \\
\hline & $\begin{array}{l}\text { Graduated from junior college } \\
\text { or college }\end{array}$ & 36 & 23.3 \\
\hline \multirow{2}{*}{$\begin{array}{l}\text { Number of staff members working under } \\
\text { the subject's supervision }\end{array}$} & Five or fewer & 48 & 55.6 \\
\hline & Six or more & 38 & 44.4 \\
\hline
\end{tabular}

objectives", and "personal interviews", which were infrequent in the PDCA cycle activity, increased by $12.8 \%$, $11.7 \%$, and $10.5 \%$, respectively. The items, "defining individual objectives" and "orienting staff to define objectives" showed statistically significant differences $(p<$ $0.05)$.

\section{DISCUSSION}

Training to help novice PHNs acquire practical skills is an important task that senior PHNs perform through inservice education. Although the participants were busy with their routine work, we believe that this leadertraining program, which introduced an action-learning approach, was effective. The important points in action learning are to solve problems effectively and efficiently and to create unique and continuous strategies. Five items that should be dealt with in action-learning are as follows: highly important problems, urgent problems, problems that we face in our personal lives, problems that we can solve on our own, and problems related to what the group has the authority to solve [14]. In-service education for PHNs in Japan satisfies these requirements; therefore, it can be expected that in-service education will become more effective by using the action-learning approach.

We consider that the implementation method used in this program can be helpful and effective for in-service education for PHNs not only in Japan but also in other countries because it makes it possible for PHNs to conduct OJT while performing their usual work-related tasks. Spiral learning of Off-JT to OJT and OJT to Off-JT is an 
Table 2. Comparison before and after the program on PHN leaders' management practice.

\begin{tabular}{|c|c|c|c|c|c|}
\hline & \multirow{2}{*}{ Management practice } & & \multicolumn{2}{|c|}{ Program } & \multirow{2}{*}{$\frac{\mathrm{n}=86 \text { persons }(\%)}{\text { Results }}$} \\
\hline & & & Before & After & \\
\hline \multirow{10}{*}{ PDCA activity } & \multirow{2}{*}{ I define individual objectives. } & Non-practical & $60(69.8)$ & $49(57.0)$ & \multirow{2}{*}{$*$} \\
\hline & & Practical & $26(30.2)$ & $37(43.0)$ & \\
\hline & \multirow{2}{*}{$\begin{array}{l}\text { I provide staff orientation on how to deal } \\
\text { with future objectives. }\end{array}$} & Non-practical & $63(73.3)$ & $53(61.6)$ & \multirow{2}{*}{$*$} \\
\hline & & Practical & $23(26.7)$ & $33(38.4)$ & \\
\hline & \multirow{2}{*}{$\begin{array}{l}\text { I confirm the details of each staff } \\
\text { member's activities and give advice. }\end{array}$} & Non-practical & $28(32.6)$ & $22(25.6)$ & \multirow{2}{*}{ NS } \\
\hline & & Practical & $58(67.4)$ & $64(74.4)$ & \\
\hline & \multirow{2}{*}{$\begin{array}{l}\text { I evaluate each staff member's } \\
\text { achievements and results. }\end{array}$} & Non-practical & $44(51.2)$ & $35(40.7)$ & \multirow{2}{*}{ NS } \\
\hline & & Practical & $42(48.8)$ & $51(59.3)$ & \\
\hline & \multirow{2}{*}{ I conduct personal interviews. } & Non-practical & $69(80.2)$ & $63(73.3)$ & \multirow{2}{*}{ NS } \\
\hline & & Practical & $15(17.4)$ & $23(26.7)$ & \\
\hline \multirow{6}{*}{ Coaching approach } & \multirow{2}{*}{$\begin{array}{l}\text { I have a positive approach toward the } \\
\text { ideas of staff members. }\end{array}$} & Non-practical & $12(14.0)$ & $5(5.8)$ & \multirow{2}{*}{ NS } \\
\hline & & Practical & $74(86.0)$ & $81(94.2)$ & \\
\hline & \multirow{2}{*}{$\begin{array}{l}\text { I identify and inform them about } \\
\text { personal changes. }\end{array}$} & Non-practical & $23(26.7)$ & $22(25.6)$ & \multirow{2}{*}{ NS } \\
\hline & & Practical & $63(73.3)$ & $64(74.5)$ & \\
\hline & \multirow{2}{*}{$\begin{array}{l}\text { I advise staff members to think for } \\
\text { themselves about problem solving. }\end{array}$} & Non-practical & $32(37.2)$ & $25(29.1)$ & \multirow{2}{*}{ NS } \\
\hline & & Practical & $54(62.8)$ & $61(70.9)$ & \\
\hline
\end{tabular}

Practical: "Sometimes" and "Always" (responses 3 and 4), Non-practical: "Rarely" and "Never" (responses 1 and 2). McNemar test *: p < 0.05; NS: not significant.

effective way to improve competence [15]. In other words, focusing on the skills that PHNs want to learn, setting goals, and combining them with the method of this program is helpful and effective.

Before the intervention program, the frequency with which PHN leaders employed management skills with individual staff members was low. In particular, the frequencies of such proactive strategies as leaders "defining individual objectives," "orienting staff to define objecttives," and conducting "personal interviews," in the PDCA cycle activity were low.

This study deals with how PHN leaders manage their staff, and there is a common concern that managing and coaching staff are actions or behaviors with which leaders should be occupied. Evaluations of actual activities related to this idea have been reported [16]. "Defining individual objectives" is a basic behavior that is carried out based on the evaluation of activity in a learning cycle, which includes "defining objectives," "carrying them out," and "evaluating them" [11]. Without appropriate assessment of the staff, objectives cannot be defined, so such assessment is a priority.

The results showed that PHN leaders tended to confirm activity, evaluate achievement, and focus on the contents of the activity; which indicated that defining individual objectives, orienting staff to define objectives, and focusing on individual competence were not frequently carried out. This is an area where improvements are possible. PHN leaders require the capacity to lead and to define appropriate objectives for staff members and to manage their activities. Items in the coaching approach such as having a positive approach towards each staff member's ideas and identifying and informing them about personal changes, were generally carried out. Basic skills in coaching involve listening to others and reviewing feedback [17]. The frequency with which coaching skills were employed was assumed to be high because these are skills PHNs learn at the basic education level as a communication skill in human relations training.

Approximately $70 \%$ of the subjects in this study had a job title and approximately half of these were in charge of training their staff. When carrying out a skills-training plan through OJT, collaboration within the organization is required. Therefore, it is possible that leaders in this study requested cooperation from the organization. It is reported that PHN leaders must take responsibility and provide authority for their own organization while managing each staff member, so that they can demonstrate 
their competence in practicing management and promoting in-service education [13]. Therefore, it can be suggested that to reform organizations in the future and promote in-service education it will be important to enhance the management skills of PHN leaders.

In Japan, PHNs are so busy with their duty schedules that there is little time to spare for in-service education for novice PHNs, nor has a comprehensive system for in-service education been established. PHN leaders play an important role in establishing a system for in-service education and finding ways to train novice PHNs efficiently. Therefore, it is of fundamental importance to improve the competence of PHN leaders in managing individual staff members. Competencies of PHNs in the United States are stipulated in the Core Competencies for Public Health Professionals [18]. According to this document, the generalist level competencies reflect completion of education at the baccalaureate level and the specialist level competencies reflect completion of education at the master's level. We found no papers that defined competencies of PHNs at levels higher than the master's degree. A study concerning a proposal for in-service education for PHNs who work for public health centers in a state in the United States suggested that the curriculum of professional public health studies and roles of PHNs should be included in in-service training [19]. It is necessary to clarify professional competencies common to PHNs wherever they work. Management skills of PHNs in Japan are an important competency related to leadership in administrative sectors as well as a required competency common to all PHNs throughout the world. A study by Zabner et al. shows that PHNs working in public health centers expect to have support from their organization while performing their usual tasks with busy schedules and also expect state or national public health organizations to conduct professional education [19]. Therefore, it is necessary for each country to examine in-service education, create a system to improve PHN leaders' competencies, and establish a program for in-service education.

\section{LIMITATIONS}

A limitation of this study is that the number of analyzable subjects was fewer than that of the program's actual participants. This is because this program was a one-year program and some of the participants were transferred to other workplaces during the program, which prevented us from acquiring sufficient data after the program ended. In addition, since the effects of the program were not necessarily expected to have been visible right after the program ended, the long-term effects will not be observable for some time. We would like to emphasize the importance of promoting leader-training programs for in- service education that can be readily applied in the workplace.

\section{CONCULUSIONS}

Items in the coaching approach that were employed by many participants before the program did not show a significant increase in frequency after the program. However, one of the benefits of this program was that the items, "defining individual objectives," and "orientating staff to define objectives," which were less frequently carried out in PDCA cycle activity before the program, showed significant increases after the program was completed.

The results of this study suggest that the program structure used here, which grades processes to understand the importance of: PHN training, creating a PHN training plan and the methods to carry it out in workplaces, as well as to assess the plan in group training and to obtain feedback; was very effective at improving these activities, focusing on individual competence in the PDCA cycle. Reviewing one's own practices and evaluating them objectively makes it possible to improve one's ability (Spencer et al. 1993). Thus, it is essential to structure a program that offers an opportunity to put these skills into practice in the workplace and to review the results.

\section{ACKNOWLEDGEMENTS}

This study was supported by Grants-in-Aid for Scientific Research (Global Health Risk Management Study H17-Health-General-013), Ministry of Health, Labour and Welfare (2005-2007) of Japan. The authors very much appreciate the collaboration of PHN leaders who participated in this study as well as those who planned and practiced in-service education.

\section{REFERENCES}

[1] Ministry of Health, Labour and Welfare (2007) Hoken/eisei gyouseihoukoku 2006-2007. Kouseitoukei Kyoukai Press, Toyko.

[2] Ministry of Health, Labour and Welfare (2009) Hoken/eisei gyouseihoukoku 2008-2009. Kouseitoukei Kyoukai Press, Toyko.

[3] Sasaki, M.II.K., Kanagawa, K., Hirano, K. and Saitou, E. (2004) Hokenshi gyoumu youran. 2nd Edition, Nihon Kango Kyoukai Press, Tokyo.

[4] Saeki, K., Izumi H., Uza, M. and Murashima, S. (2007) Factors associated with the professional competencies of public health nurses employed by local government agencies in Japan. Public Health Nursing, 24, 449-457. doi:10.1111/j.1525-1446.2007.00655.x

[5] Ueda I., Saeki, K., Hirano M. and Honda H. (2011) The actual situation of public health nurses schools of education for training about policy in Japan. Journal of Japan 
Academy of Community Health Nursing, 14, 85-92.

[6] Abrams, S.E. (2004) From function to competency in public health nursing, 1931 to 2003. Public Health Nursing, 21, 507-510. doi:10.1111/j.0737-1209.2004.021514.x

[7] Ortega, R., Johnson, K.R. and D'Argenio, C. (1991) Management training effects on nurse manager leadership behavior. Nursing Economics, 9, 249-254.

[8] Kleinman, C. (2004) The relationship between managerial leadership behaviors and staff nurse retention. Hospital Topics, 82, 2-9. doi:10.3200/HTPS.82.4.2-9

[9] Izumi, H., Yokomizo, T., Saeki, K., Uza, M., Oono, M., Ookura, M. and Ooyanagi, T. (2004) Examination of in-service education program for mid-management leaders. Hokkaido Journal of Public Health, 18, 135-141.

[10] Sandberg, J. (2000) Understanding human competence at work: An interpretative approach. The Academy of Management Journal, 43, 9-25. doi:10.2307/1556383

[11] Collins, J., (1993) Management: Tasks, responsibilities, practices. Harper Collins Publishers Press, New York.

[12] Tee, S.R., Jowett, R.M. and Carter, B.-C. (2009) Evaluation study to ascertain the impact of the clinical academic coaching role for enhancing student learning experience within a clinical masters education programme. Nurse Education in Practice, 9, 377-382. doi:10.1016/j.nepr.2008.11.006

[13] Saeki, K., Kawaharada, M., Izumi, H., Seki, M., Ueda, I. and Hirano, M. (2009) Developing educational organization through an on-the-job training program. Journal of Japan Academy of Community Health Nursing, 11, 52-58.

[14] Frank, H.D. (1997) Will the future of management development involve action learning? Action Learning and Action Research Journal, 2, 3-20.

[15] Spencer, L.M. Jr. and Spencer, S.M. (1993) Competence at work: Models for superior performance. John Wiley \& Sons, Inc., New York.

[16] Berkowitz, B., Dahl, J., Guirl, K., Kostelecky, B.J., McNeil, C. and Upenieks, V. (2001) Public health nursing leadership. American Nurses Publishing Press, Washington DC.

[17] Whitworth, L., Kimsey-House, H., Sandahl, P. and Sandahl, P. (2007) Co-active coaching: New skills for coaching people toward success in work and life. Davies-Black Publishing Press, Boston.

[18] Quad Council of Public Health Nursing Organizations (2004) Public health nursing competencies. Public Health Nursing, 21, 443-452. doi:10.1111/j.0737-1209.2004.021508.x

[19] Zabner, S.J. and Gredig, Q.-N.B. (2005) Improving public health nursing education: Recommendations of local public health nurses. Public Health Nursing, 22, 445-450. doi:10.1111/j.0737-1209.2005.220510.x 